\title{
IMPLEMENTASI KNOWLEDGE MANAGEMENT DALAM SISTEM INFORMASI PERPUSTAKAAN (Studi Kasus di Perpustakaan Nasional Republik Indonesia)
}

\author{
Nurshifa Fauziyah \\ Mahasiswa Program Pascasarjana UIN Sunan Kalijaga Yogyakarta \\ Program Studi Interdisciplinary Islamic Studies Konsentrasi Ilmu Perpustakaan dan Informasi \\ Email: nurshifa9@gmail.com
}

\begin{abstract}
Abstrak
Artikel ini membahas tentang penerapan knowledge management dalam sistem informasi perpustakaan di Perpustakaan Nasional RI. Artikel ini menunjukkan bahwa Perpustakaan Nasional RI sudah menerapkan knowledge management dalam sistem informasinya yaitu dengan menciptakan OneSearch atau IOS. Penulis berargumen bahwa penerapan knowledge management yang dilakukan oleh Perpustakaan Nasional RI terhadap sistem informasinya didasari oleh adanya kesadaran manusia (pengelola Perpustakaan Nasional RI) atas pengetahuan dimana apa yang "diketahui" oleh masyarakat sebagai "kenyataan" dalam kehidupan sehari-hari kemudian diarahkan perhatiannya pada pembentukan kenyataan oleh masyarakat (social constructian of reality). Artikel ini berkontribusi pada kajian-kajian penerapan knowledge management dalam sistem informasi perpustakaan yang dalam pembentukannya didasari oleh kesadaran manusia pada sosiologi pengetahuan.
\end{abstract}

Kata kunci: knowledge management, sisten informasi perpustakaan, sosiologi pengetahuan

\begin{abstract}
This article discusses the application of knowledge management in library information systems in the National Library of the Republic of Indonesia. This article shows that the National Library of the Republic of Indonesia has implemented knowledge management in its information system by creating OneSearch or IOS. The author argues that the application of knowledge management carried out by the National Library of the Republic of Indonesia to its information system is based on the existence of human awareness (the manager of the National Library of the Republic of Indonesia) on knowledge where what is "known" by the community as "reality" is directed on the formation of reality by society (social constructian of reality). This article contributes to studies on the application of knowledge management in library information systems which in its formation are based on human consciousness in the sociology of knowledge.

Keywords: knowledge management, library information systems, sociology of knowledge
\end{abstract}

\section{PENDAHULUAN}

Sebelum lahir istilah knowledge management, kita masih dibingungkan dengan perbedaan makna antara data, informasi, dan pengetahuan serta hubungan antar ketiganya. Namun, seiring perkembangan zaman, mulai muncul istilah knowledge management dimana keberadaannya memberikan penjelasan yang jelas terhadap ketiga hal tersebut. Ada semacam proses distilasi dari data menuju informasi yang kemudian menjadi pengetahuan 
(knowledge). Artimya bahwa pengetahuan memiliki kedudukan lebih tinggi dimana knowledge lebih dalam, lebih luas, dan lebih kaya dari data dan informasi.

Disini letak peran knowledge management terlihat bahwa knowledge management memiliki peran yang beragam sesuai dengan perkembangan teknologi yang membuat masing-masing lembaga/instansi/organisasi/perusahaan memiliki definisi dan fungsi knowledge management yang disesuaikan dengan strategi dan kerangka yang digunakan dalam implementasi knowledge management tersebut.

Perpustakaan merupakan salah satu lembaga pelayanan informasi yang mengimplementasikan knowledge management dalam pengelolaan perpustakaan yang dalam hal ini adalah pengaplikasian sistem informasi perpustakaan. Di dalam sistem informasi perpustakaan terjadi proses management knowledge yang tujuan utamanya adalah memberikan pelayanan yang efektif dan efisien bagi penggunanya.

Sistem informasi perpustakaan adalah sebuah sistem terpadu atau terintegrasi untuk menyajikan informasi guna mendukung fungsi operasional, manajemen, dan pengambilan keputusan dalam sebuah perpustakaan. ${ }^{1}$ Sehingga pengimplementasian knowledge management dalam sistem informasi perpustakaan menjadi hal yang penting untuk diterapkan dalam perpustakaan dalam rangka optimalisasi pelayanan informasi di perpustakaan.

Artikel ini akan membahas tentang penerapan knowledge management dalam sistem informasi perpustakaan di Perpustakaan Nasional RI. Artikel ini menunjukkan bahwa Perpustakaan Nasional RI sudah menerapkan knowledge management dalam sistem informasinya yaitu dengan menciptakan OneSearch atau IOS. Penulis berargumen bahwa penerapan knowledge management yang dilakukan oleh Perpustakaan Nasional RI terhadap sistem informasinya didasari oleh adanya kesadaran manusia (pengelola Perpustakaan Nasional RI) atas pengetahuan dimana apa yang "diketahui" oleh masyarakat sebagai "kenyataan" dalam kehidupan sehari-hari kemudian diarahkan perhatiannya pada pembentukan kenyataan oleh masyarakat (social constructian of reality). Artikel ini berkontribusi pada kajian-kajian penerapan knowledge management dalam sistem informasi perpustakaan yang dalam pembentukannya didasari oleh kesadaran manusia pada sosiologi pengetahuan.

1 Syifaun Nafisah, Konsep Dasar Sistem Informasi, Dalam materi perkuliahan program studi Interdisiplinary Islamic Studies konsentrasi Ilmu Perpustakaan 


\section{METODE}

Metode yang digunakan penulis dalam artikel ini yaitu deskriptif kualitatif dengan mengkaji lebih dalam mengenai implementasi knowledge management pada sistem informasi perpustakaan dengan mengkaitkan pada teori sosiologi pengetahuan untuk kemudian dideskripsikan secara terstruktur, sistematis dan mendalam.

\section{PEMBAHASAN}

\section{Knowledge management}

American Productivity and Quality Centre (APQC) menjelaskan knowledge management sebagai pendekatan-pendekatan sistematik yang membantu muncul dan mengalirnya informasi dan knowledge kepada orang yang tepat pada saat yang tepat untuk menciptakan nilai. ${ }^{2}$ Secara konseptual, Knowledge management merupakan kegiatan organisasi dalam mengelola pengetahuan sebagai aset, diperlukan upaya penyaluran pengetahuan yang tepat kepada orang yang tepat dan dalam waktu yang cepat, hingga mereka bisa saling berinteraksi, berbagi pengetahuan dan mengaplikasikannya dalam pekerjaan sehari-hari demi peningkatan kinerja organisasi. ${ }^{3}$

\section{Manfaat Implementasi Knowledge management}

Knowledge merupakan aset kunci agar suatu organisasi memiliki keunggulan kompetitif yang kontinu. Keunggulan kompetitif tersebut diperoleh dari dampak implementasi knowledge management terhadap berbagai bidang berikut ini ${ }^{4}$ :

1) Bidang operasi dan pelayanan

Perusahaan yang memiliki knowledge worker adalah perusahaan yang memiliki basis customer knowledge yang terkelola dengan baik. Customer knowledge ini dapat diakses oleh pekerjanya serta dapat membantu mereka dalam memberikan pelayanan terbaik kepada pelanggannya.

2) Bidang pengembangan kompetensi personil

Proses pembelajaran terjadi dalam siklus yang kontinu. Proses ini berawal dari akuisisi knowledge yang kemudian diaplikasikan dalam proses bisnis organisasi. Knowledge yang diaplikasikan potensial memunculkan knowledge yang baru melalui

${ }^{2}$ Paul L. Tobing, Knowledge Management: Konsep Arsitektur dan Implementasi, (Yogyakarta: Graha Ilmu, 2007), 8

${ }^{3}$ Harjanto Prabowo, Knowledge Management Di Perguruan Tinggi, Dalam Jurnal Binus Business Review Vol.1 No.2 November 2010, 411

${ }^{4}$ Paul L. Tobing, Knowledge Management: Konsep Arsitektur dan Implementasi, (Yogyakarta: Graha Ilmu, 2007), 24-28 
proses knowledge creation (penciptaan knowledge). Knowledge ini kemudian dipelihara dan dishare kembali untuk dapat diakuisisi dan dimanfaatkan secara luas. Siklus inilah menjadi proses utama dalam knowledge management yaitu berupa proses-proses: knowlegde creation, knowledge retention, knowledge transfer/sharing, dan knowledge utilisation.

3) Bidang pemeliharaan ketersediaan knowledge

Skill dan knowledge yang dimiliki oleh pekerja dalam sebuah perusahaan perlu dikelola oleh perusahaan untuk menjamin tidak terjadinya knowledge loss. Knowledge loss adalah suatu kondisi dimana perusahaan kehilangan knowledge yang dibutuhkannya, meskipun knowledge tersebut sebelumnya sudah pernah dimiliki dan dipergunakan oleh perusahaan tersebut.

4) Bidang inovasi dan pengembangan produk

Salah satu produk dari knowledge management adalah proses pembelajaran yang berimplikasi terhadap peningkatan kemampuan inovasi yaitu dengan terciptanya knowledge baru. Inovasi yang dikombinasikan dengan kebutuhan pelanggan akan menjadi solusi atau produk yang efektif dalam mengatasi permasalahan yang dihadapi oleh pelanggan.

\section{Faktor-faktor Penting dalam Implementasi Knowledge management}

1) Manusia

Pada hakekatnya knowledge berada di dalam pikiran manusia berupa tacit knowledge. Di samping sebagai sumber knowledge, manusia juga pada hakekatnya merupakan pelaku dari proses-proses yang ada di dalam knowledge management.

\section{2) Leadership}

Untuk suksesnya implementasi knowledge management, para pemimpin harus mengerahkan kapasitas intelektual dan sumber daya yang di bawah kendalinya dalam menginspirasi, menyusun dan terjun langsung mengkonduktori implementasi knowledge management untuk mewujudkan visinya.

3) Teknologi

Perkembangan teknologi informasi (TI) yang sudah merasuk ke semua aspek kegiatan manusia membuat penggunaan teknologi informasi menjadi salah satu enabler dari knowledge management. Selain berfungsi sebagai media utama pendistribuan knowledge, penggunaan teknologi IT dalam knowledge 
management juga sangat berperan dalam mengeksekusi berbagai proses di knowledge management yaitu:

- Capture, generate atau akuisisi knowledge

- Kodifikasi knowledge

- Knowledge maintenance (validasi, pemeliharaan integritas knowledge)

- Security dari knowledge

- Memonitor pemanfaatan knowledge.

4) Organisasi

Organisasi berkaitan dengan penanganan aspek operasional dari aset-aset knowledge, termasuk fungsi-fungsi, proses-proses, struktur organisasi formal dan informal ukuran dan indikator pengendalian proses penyempurnaan, dan rekayasa proses bisnis.

5)

\section{Learning}

Proses learning menjadi sangat penting dalam knowledge management karena melalui proses inilah diharapkan muncul ide-ide, inovasi dan knowledge baru, yang menjadi komoditas utama yang diproses dalam knowledge management. ${ }^{5}$

\section{Sistem Informasi Perpustakaan}

Sistem informasi perpustakaan adalah sebuah sistem terpadu atau terintegrasi untuk menyajikan informasi guna mendukung fungsi operasional, manajemen, dan pengambilan keputusan dalam sebuah perpustakaan. ${ }^{6}$

Secara spesifik definisi sistem informasi perpustakaan adalah suatu penerapan teknologi informasi digunakan sebagai sistem informasi manajemen perpustakaan. Bidang pekerjaan yang dapat diintegrasikan dengan sistem informasi perpustakaan adalah pengadaan, inventarisasi, katalogisasi, sirkulasi bahan pustaka, pengelolaan anggota, statistik dan lain sebagainya. ${ }^{7}$ Fungsi ini sering diistilahkan sebagai bentuk Automasi Perpustakaan. Sistem automasi perpustakaan adalah implementasi teknologi informasi pada pekerjaan-pekerjaan administratif di perpustakaan agar lebih efektif dan efisien. Adapun kegiatan-kegiatan yang ada dalam automasi perpustakaan diantaranya: pengadaan,

${ }^{5}$ Ibid, 28-32

6 Syifaun Nafisah, Konsep Dasar Sistem Informasi, Dalam materi perkuliahan program studi Interdisiplinary Islamic Studies konsentrasi Ilmu Perpustakaan

7 Barra Sulthani, Sistem Indormasi perpustakaan Fakultas Kedokteran dan Kesehatan Universitas Muhammadiyah Jakarta, Dalam Skripsi Prodi Teknik Informatika Fakultas Sains dan Teknologi UIN Syarif Hidayatullah Jakarta 2008 
inventarisasi, pengolahan, sirkulasi, penyiangan, manajemen keanggotaan, OPAC, statistik pelaporan, dan lain-lain. Sehingga, yang menjadi fokus sistem informasi perpustakaan adalah:

- Mendukung layanan secara efektif bagi pengguna,

- Manajemen pengadaan,

- Manajemen layanan yang diberikan oleh perpustakaan dan badan-badan lainnya yang menyelenggarakan akses terhadap koleksi-koleksi dokumen. ${ }^{8}$

\section{Implementasi Knowledge management dalam Sistem Informasi Perpustakaan}

Salah satu lembaga perpustakaan yang mengimplementasikan knowledge management dalam sistem informasi perpustakaan adalah Perpustakaan Nasional RI.

Perpustakaan Nasional Republik Indonesia (Perpusnas) adalah Lembaga Pemerintah Nonkementerian yang melaksanakan tugas pemerintahan dalam bidang perpustakaan yang berfungsi sebagai perpustakaan pembina, perpustakaan rujukan, perpustakaan deposit, perpustakaan penelitian, perpustakaan pelestarian, dan pusat jejaring perpustakaan, serta berkedudukan di ibukota negara. Perpustakaan Nasional berada di Jalan Medan Merdeka Selatan 11, Jakarta dan berada di bawah dan bertanggung jawab kepada Presiden. Pada tanggal 14 September 2017, Presiden Joko Widodo meresmikan Perpusnas baru yang merupakan perpustakaan nasional tertinggi di dunia (126,3 meter) dengan 27 lantai, termasuk tiga lantai parkir bawah tanah (basement). ${ }^{9}$ Perpustakaan Nasional RI sebagai lembaga perpustakaan tertinggi di Indonesia memiliki perhatian yang cukup besar terhadap knowledge management yaitu dengan menciptakan sistem informasi perpustakaan berbasis web; Indonesia OneSearch.

Indonesia OneSearch atau IOS adalah sebuah pintu pencarian tunggal untuk semua koleksi publik dari perpustakaan, museum, dan arsip di seluruh Indonesia. Selain itu, portal ini juga menyediakan akses ke sumber elektronik internasional (e-resources) yang dilanggan oleh Perpusnas RI untuk semua anggota yang terdaftar. Untuk bergabung dengan IOS, setiap repositori harus menyediakan API berbasis OAI-PMH (Open Archive Initiatives), sebuah protokol pengambilan metadata yang sudah digunakan oleh $75 \%$ lebih repositori di dunia. ${ }^{10}$

8 Syifaun Nafisah, Konsep Dasar Sistem Informasi, Dalam materi perkuliahan program studi Interdisiplinary Islamic Studies konsentrasi Ilmu Perpustakaan

${ }^{9}$ https://id.wikipedia.org/wiki/Perpustakaan_Nasional_Republik_Indonesia, Diakses pada 6 Juni 2018 pukul 08.41 WIB

${ }^{10}$ http://onesearch.id/Repositories/Ios, Diakses pada 6 Juni 2018 pukul 08.50 WIB 
IOS ini adalah sebuah open acces discovery system level nasional yang mencakup sektor perpustakaan, arsip, museum, galeri, dan science park. IOS ini terintegrasi dengan katalog, repositori institusi, dan e-resource yang dilanggan Perpusnas.

IOS menyediakan Search Widget yang bertujuan untuk:

- Menghadirkan fasilitas dan hasil pencarian ke situs perpustakaan institusi mitra

- Pengguna memanfaatkan layanan IOS Search Widget untuk pencarian seluruh repositori institusinya

- Pengguna juga dihubungkan dengan repositori institusi lain melalui Central Index IOS. $^{11}$

IOS melakukan shared index dengan maksud agar institusi tidak perlu membangun server index sendiri serta institusi dapat memanfaatkan central index IOS termasuk seluruh fitur yang dimiliki IOS. Saat ini terdapat 5,873,430 entri di dalam Indonesia OneSearch. Koleksi ini dikumpulkan dengan metode harvesting otomatis dari repositori milik organisasi mitra, yang berasal dari berbagai sektor.

Melihat kebermanfaatan IOS yang diciptakan oleh Perpusnas membuat masyarakat lebih mudah dalam mengakses informasi, tentunya bagi instansi yang bermitra. Paling tidak, Perpusnas telah berusaha membangun knowledge management dengan menciptakan Indonesia OneSearch dimana dalam IOS tersebut terdapat berjuta-juta ilmu pengetahuan tersimpan dan terpelihara yang kemudian dapat diakses oleh instansi mitra.

\section{Analisis Sosiologi Pengetahuan terhadap Penerapan Knowledge Management dalam Sistem Informasi Perpustakaan}

Sosiologi pengetahuan merupakan ilmu baru yang menjadi cabang dari sosiologi yang mempelajari hubungan timbal-balik antara pemikiran dan masyarakat. Sosiologi pengetahuan menaruh perhatian pada kondisi sosial atau eksistensial pengetahuan ${ }^{12}$. Lebih lanjut dijelaskan bahwa ide-ide sosiologi pengetahuan telah dilahirkan oleh pemikir muslim, Ibnu Khaldun pada abad ke-14. Ibnu Khaldun memandang bahwa ilmu pengetahuan adalah pengetahuan yang tersistematisasikan dan semua ilmu pengetahuan adalah interdependen, artinya ilmu pengetahuan itu dipengaruhi oleh kondisi sosial. Pandangan ini selaras dengan

11 Ismail Fahmi, Indonesia OneSearch dan Biblio Metric Analysis, Dalam Workshop Indoensia OneSearch FPPTI DIY 10 Maret 2017

12 Muhyar Fanani, Metode Studi Islam: Aplikasi Sosiologi Pengetahuan Sebagai Cara Pandang, (Yogyakarta: Pustaka Pelajar, 2010), 32 
komposisi Karl Marx yang menyatakan bahwa kesadaran manusia ditentukan oleh keberadaan sosialnya ${ }^{13}$.

Sosiologi pengetahuan dikembangkan lebih lanjut oleh Peter L. Berger dan Thomas Luckman dalam bukunya The Social Construction of Reality: A Treatise in The Sociology of Knowledge. Dengan pengaruh yang berbeda, sosiologi pengetahuan Berger pun sedikit berbeda dari ilmuwan terdahulu. Untuk kepentingan penyusunan teorinya, Berger dan Luckmann amat mendasarkan diri pada dua gagasan sosiologi pengetahuan yaitu "realitas" dan "pengetahuan". "Realitas" mereka artikan sebagai kualitas yang melekat pada fenomena yang kita anggap berada di luar kehendak kita. Dalam arti, "realitas" merupakan fakta sosial yang bersifat eksternal, umum, dan mempunyai kekuatan memaksa kesadaran masingmasing individu. Sedangkan "pengetahuan" diartikan sebagai keyakinan bahwa suatu fenomena itu riil dan mereka mempunyai karakteristik tertentu. Dalam arti, pengetahuan merupakan realitas yang hadir dalam kesadaran individu (realitas yang bersifat subjektif). ${ }^{14}$

Secara mendasar memang semua pemikir sosial yang menggunakan sosiologi pengetahuan menyadari bahwa ada latar belakang yang membentuk sebuah realitas sosial. Akan tetapi bagi Berger, sosiologi pengetahuan tidak lagi hanya menekuni sejarah intelektual dalam arti sejarah gagasan-gagasan. Sosiologi pengetahuan harus menekuni segala sesuatu yang dianggap sebagai "pengetahuan" dalam masyarakat. Tiap orang dalam masyarakat berpartisipasi dalam "pengetahuan"-nya, dengan cara tertentu. Dengan kata lain, hanya segelintir orang saja yang menekuni tentang penafsiran teoritis atas dunia, tetapi setiap orang bagaimanapun hidup dalam satu dunia, apa pun jenisnya. Karena itu, pertamatama sosiologi pengetahuan harus menyibukkan diri dengan apa yang "diketahui" oleh masyarakat sebagai "kenyataan" dalam kehidupan mereka sehari-hari yang tidak teoritis atau yang prateoritis. Dan oleh karena itu, sosiologi pengetahuan harus mengarahkan perhatiannya pada pembentukan kenyataan oleh masyarakat (social construction of reality $)^{15}$.

Dari penjelasan di atas dapat dipahami bahwa sosiologi pengetahuan yang dikembangkan oleh Berger dan Luckmann adalah sebuah disiplin sosiologi yang mengembalikan realitas sosial pada dasar utamanya, yaitu manusia. Sosiologi pengetahuan memahami kenyataan manusia sebagai kenyataan yang dibangun secara sosial ${ }^{16}$.

${ }^{13}$ Peter L. Berger dan Thomas Luckman, Tafsir Sosial Atas Kenyataan: Risalah Tentang Sosiologi Pengetahuan, terj. Hasan Basari, (Jakarta: LP3ES, 2012), 7

${ }^{14}$ Ibid, 1

${ }^{15}$ Ibid, 20-21

16 Ibid, 255 
Penerapan knowledge management yang dilakukan oleh Perpustakaan Nasional RI pada sistem informasinya berangkat dari adanya kenyataan atas kebutuhan informasi oleh berbagai lapisan masyarakat yang diiringi dengan perkembangan teknologi informasi yang begitu pesat. Ini menunjukkan bahwa terjadi realitas sosial yang berada di luar kehendak manusia. Kenyataan bahwa perkembangan teknologi dan informasi sekarang ini tidak dapat dibendung lagi oleh manusia. Ini merupakan fakta sosial yang bersifat eksternal dan memiliki kekuatan memaksa kesadaran masing-masing individu.

Di sisi yang lain, pengetahuan diartikan sebagai keyakinan bahwa suatu fenomena itu riil dan mereka mempunyai karakteristik tertentu. Dalam hal ini, Perpustakaan Nasioanal RI mengambil peran atas kesadaran pengetahuannya terhadap realitas sosial yaitu dengan menerapkan knowledge management dalam sistem informasinya dengan menciptakan OneSearch atau IOS sebagai bentuk upaya memberikan pelayanan informasi yang efektif dan efisien.

\section{PENUTUP}

Dari pembahasan yang sudah dipaparkan di atas, dapat dipahami bahwa kemampuan knowledge management sangat diperlukan untuk menciptakan organisasi yang lebih maju. Perpustakaan menjadi salah satu lembaga yang mengimplementasikan knowledge management dalam sistem informasinya. Hal ini sangat tepat dilakukan karena melihat perpustakaan adalah lembaga yang bergerak dalam bidang informasi dan pengetahuan.

Perpustakaan Nasional RI adalah lembaga perpustakaan tertinggi di Indonesia yang berhasil mengimplementasikan knowledge management dalam sistem informasinya yaitu dengan menciptakan Indonesia OneSearch. Indonesia OneSearch merupakan pintu pencarian tunggal untuk semua koleksi publik dari perpustakaan, museum, dan arsip di seluruh Indonesia. IOS mengumpulkan koleksi dari seluruh organisasi mitra yang kemudian dapat diakses oleh mitra-mitra yang lain. Hal ini menunjukkan adanya proses management knowledge yang dilakukan oleh Perpustakaan Nasional RI yang memberikan manfaat yang besar bagi organisasi mitra dan masyarakat umum.

Penerapan knowledge management yang dilakukan oleh Perpustakaan Nasional RI pada sistem informasinya berangkat dari adanya kenyataan atas kebutuhan informasi oleh berbagai lapisan masyarakat yang diiringi dengan perkembangan teknologi informasi yang begitu pesat yang kemudian disebut sebagai realitas sosial. Selanjutnya, Perpustakaan Nasioanal RI mengambil peran atas kesadaran pengetahuannya terhadap realitas sosial yaitu dengan menerapkan knowledge management dalam sistem informasinya dengan 
menciptakan OneSearch atau IOS sebagai bentuk upaya memberikan pelayanan informasi yang efektif dan efisien.

\section{DAFTAR PUSTAKA}

Berger, Peter L. dan Thomas Luckman, Tafsir Sosial Atas Kenyataan: Risalah Tentang Sosiologi Pengetahuan, terj. Hasan Basari, Jakarta: LP3ES, 2012

Fahmi, Ismail, Indonesia OneSearch dan Biblio Metric Analysis, Dalam Workshop Indonesia OneSearch FPPTI DIY 10 Maret 2017

Fanani, Muhyar, Metode Studi Islam: Aplikasi Sosiologi Pengetahuan Sebagai Cara Pandang, Yogyakarta: Pustaka Pelajar, 2010

Nafisah, Syifaun, Konsep Dasar Sistem Informasi, Dalam materi perkuliahan program studi Interdisiplinary Islamic Studies konsentrasi Ilmu Perpustakaan

Prabowo, Harjanto, Knowledge Management Di Perguruan Tinggi, Dalam Jurnal Binus Business Review Vol.1 No.2 November 2010

Sulthani , Barra, Sistem Indormasi perpustakaan Fakultas Kedokteran dan Kesehatan Universitas Muhammadiyah Jakarta, Dalam Skripsi Prodi Teknik Informatika Fakultas Sains dan Teknologi UIN Syarif Hidayatullah Jakarta 2008

Tobing, Paul L., Knowledge Management: Konsep Arsitektur dan Implementasi, Yogyakarta: Graha Ilmu, 2007

https://id.wikipedia.org/wiki/Perpustakaan_Nasional_Republik_Indonesia, Diakses pada 6 Juni 2018 pukul 08.41 WIB

http://onesearch.id/Repositories/Ios, Diakses pada 6 Juni 2018 pukul 08.50 WIB 